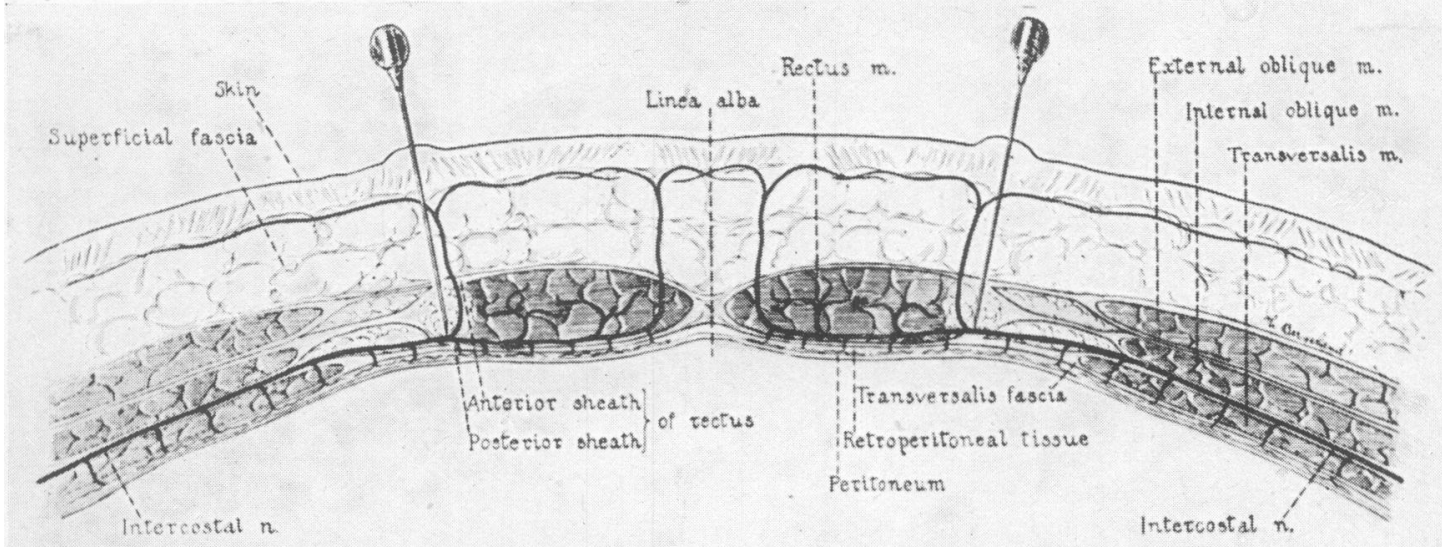

Fig. 30.3.-Cross-section of part of the anterior abdominal wall, showing the method of making deep injections within the rectus sheath.

Reproduced by kind permission of Messrs. W. B. Saunders Co.

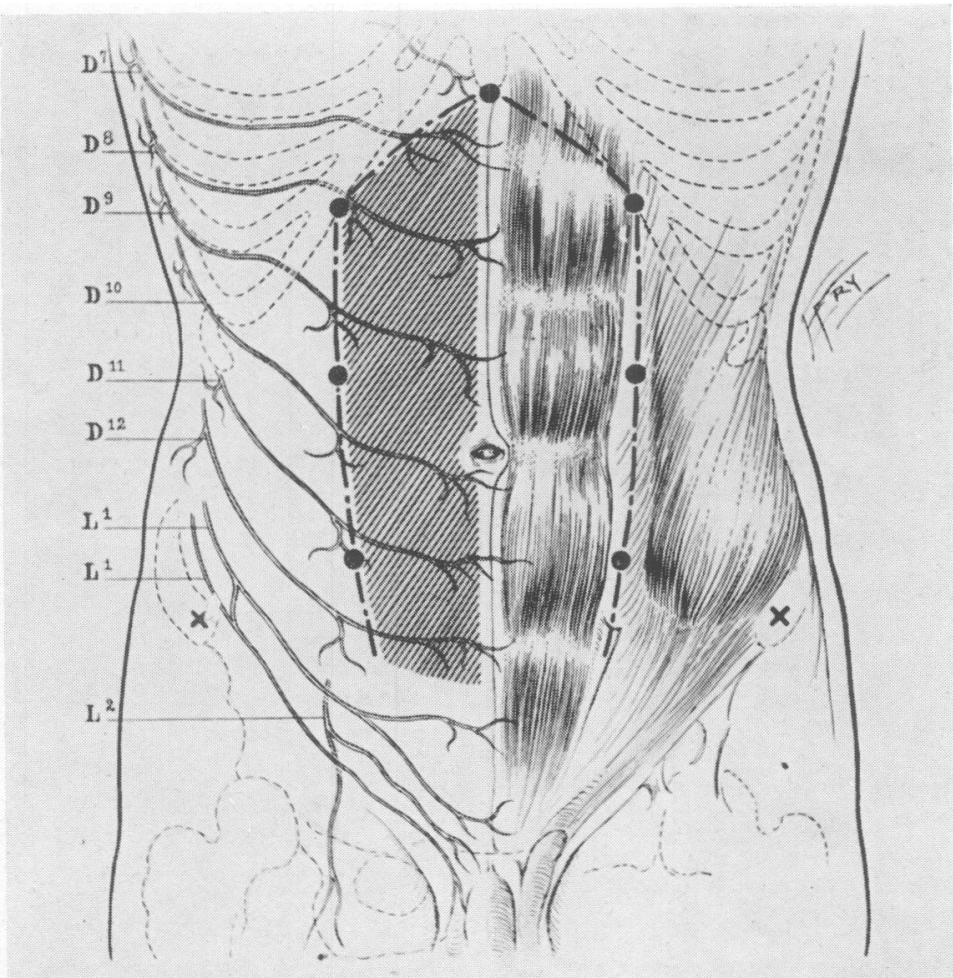

Fig. 304.-Extensive abdominal field-block. The dots mark the sites of puncture along the lateral margin of the rectus sheath; the dotted lines, the subcutaneous infiltration.

Reproduced by kind permission of Messrs. W. B. Saunders Co. 


\section{ANAESTHESIA FOR GASTRIC OPERATIONS}

\author{
By. J. Alfred Lee, M.R.C.S., L.R.C.P., \\ M.M.S.A., D.A.
}

(Hon. Anaesthetist, Southend General Hospital; Anaesthetic Specialist, E.M.S.)

The ideal anaesthetic for the various operations upon the stomach has not yet been 'found. Any method employed should fulfil the following conditions and should provide:-

A. Good relaxation of the muscles of the abdominal wall and of the peritoneum. This makes exposure of the upper abdominal organs easy, and facilitates closure of the wound. Relaxation in general anaesthesia is due to depression of the motor centres in the anterior horn cells of the spinal cord which initiate impulses maintaining muscular tone. As the rectus and transversus abdominis are accessory muscles of respiration, their tone persists in planes of third-stage anaesthesia which produce complete flaccidity of the skeletal muscles of the limbs. Moreover, as the posterior fascial sheath of the rectus and transversus muscles are fused with the parietal peritoneum in the upper abdomen, these muscles must be loose when the peritoneum is sutured. Relaxation is aided in all methods of anaesthesia by raising the knees six inches off the table, and by flexing the head. There may be a place for curare as an aid to relaxation.

B. Quiet breathing. This makes the manipulations of the surgeon easier because movements of the diaphragm and intercostal muscles cause movements of the upper abdominal viscera proportional to the activity of the breathing. Conversely, the rising and falling of the diaphragm, and hence respiratory exchange, may be interfered with by packs and retractors $(\mathrm{I})$.

C. Protection from shock and circulatory depression. There are many nerve endings and plexuses in the upper abdomen, stimulation of which by traction, packing, etc., can cause shock. For this reason, upper abdominal operations cause more shock than lower.

D. Minimal disturbance of respiratory function. Anaesthetic agents can cause (a) chemical irritation with excess mucus production, e.g. ether; $(b)$ depression of the muscles of respiration which favours post-operative hypoventilation and atelectasis, e.g. high spinal and intercostal blocks; $(c)$ depression of the cough reflex, e.g. deep ether and heavy premedication.

E. Minimal interference with body chemistry. Here ether is the chief offender of the commonly used anaesthetics. It depresses liver and kidney function, makes the bowel atonic, and causes nausea and vomiting after operation.

In addition to satisfying the surgeon by attention to the above points, the aim should be to give the patient an anaesthetic that is as free as possible from unpleasantness both before and after operation. Finally the anaesthetic must not endanger life nor add to post-operative complications.

\section{Preliminary Examination}

This should be carried out where possible before $\overrightarrow{0}$ the day of operation, since estimation of the $\overrightarrow{\vec{\omega}}$ general condition of the patient is the first step $\stackrel{\vec{\rho}}{\vec{D}}$ in assessing him as an anaesthetic and surgical $\overrightarrow{8}$ risk. After that comes an estimation of the tone of the muscles of the anterior abdominal wall. Flaccid muscles can be easily relaxed whereas a $\vec{\sim}$ tight powerful belly wall will demand the use of $\tilde{\omega}_{0}$ the most potent drugs and techniques.

Respiratory function requires special notice. $\vec{\varnothing}$ The existence of a productive cough is more im- i portant than the elicitation of adventitious sounds 9 with the stethoscope.

The state of the blood, heart and vessels must be $\vec{c}$ evaluated. Here, again, the reactions of the $\frac{\bar{\sigma}}{\sigma}$ patient to the ordinary activities of life give more $\overrightarrow{0}$ useful information than the presence of physica signs. When the haemoglobin is below 50 per cerin. or when the systolic blood pressure is less that roo $\mathrm{mm}$. Hg., high spinal analgesia is likely to be hazardous. A low haemoglobin level may call for transfusion before, during or after operation. $\tilde{\partial}^{\circ}$ The condition of the liver and kidneys must not $\mathbb{Q}$ be forgotten, while the state of the teeth and the $\overrightarrow{\overrightarrow{0}}$ degree of patency of the nares may influence the 3 method of intratracheal intubation. Finally the emotional make-up of the patient together with his reactions to previous operations must be investigated so that proper premedication can be ordered.

\section{Pre-anaesthetic Preparation and Medication}

The patient should be in hospital forty-eight hours before operation so that he may become familiar with his surroundings and undergo anyo investigations that may be necessary. Glucoser given at this time will help to combat any post operative ketosis and should be taken in substantia amounts. Smoking should have been given upe at least three weeks before operation as there is evidence that the non-smoker has a much greatek chance of avoiding post-operative lung complications than the moderate or heavy smoker (2) 
The patient should be instructed in deep breathing and shown how to expand the lower chest; he will then co-operate more readily in the "shake-up" treatment after operation and lower his chances of post-operative pulmonary morbidity.

The evening before operation a sedative such as medinal gr. $\mathrm{x}$ will usually ensure a sound sleep, while omnopon gr. $\frac{1}{3}$ and scopolamine gr. $\frac{1}{150}$ given one hour before operation is a good routine premedication. Patients over sixty may become unco-operative with scopolamine and usually do better with atropin gr. $\frac{1}{75}$. If the patient is to have cyclopropane, two or three grains of nembutal should be given by mouth one and a half hours before operation, with atropin hypodermically. Nembutal depresses the respiratory centre less than omnopon or morphine and helps to prevent cardiac arrythmias (3).

\section{Agents and Methods}

Many techniques of administration are available and several agents may be used either alone or in combination the one with the other. General anaesthetics may be given by inhalati : 2 or by vein, while local analgesics can be used tú produce spinal or regional blocks.

\section{A. Inhalation.}

Ether is the best agent for use by the occasional anaesthetist, and although it is usually preceded, and may be accompanied by gas and oxygen from a machine, the open method of administration need not be frowned upon and should not be entirely neglected. Robust and obese patients may sometimes be more easily subdued with "a rag and bottle" than by a machine. The Oxford Vaporiser is a useful device for maintaining ether anaesthesia. The gas-oxygen-ether sequence may be advantageously given in a closed circuit with carbon dioxide absorption. This benefits the patient by conserving his body heat and moisture; it facilitates quiet breathing, and economises gases. Ether is well tolerated by most patients and its margin of safety is wide. While muscular relaxation is usually good, breathing is reasonably tranquil. On the other hand, deep ether anaesthesia, especially if maintained during a long operation, has many disadvantages which include upset of the body chemistry, pulmonary irritation, cardiovascular depression, slow recovery from anaesthesia, and nausea and vomiting after operation. The deeper the plane the greater are the post-operative circulatory and pulmonary complications. It should therefore be replaced whenever possible.

The important thing about good inhalation anaesthesia is an adequate airway and this is best obtained in gastric operations by the passage of an intratracheal tube, either blindly through the nose, or under direct vision through a laryngoscope, via the mouth. The latter route is usually preferable as a larger tube can be passed which makes for quieter breathing. The new Portex plastic tubes sizes eight to ten are very satisfactory for oral intubation as they will not readily kink. Preliminary topical analgesia of the larynx makes intubation easier, and once the tube is in place, laryngeal spasm ceases to play any part in the anaesthesia.

Cyclopropane possesses many advantages for operations in the upper abdomen, such as quiet breathing, freedom from irritation of the respiratory tract, and the rapidity with which induction and recovery take place. In third-plane anaesthe ia, diaphragmatic breathing is not exaggerated as it is with ether. Prolonged nausea and vomiting rarely follow cyclopropane, while the renal and hepatic functions return to normal at the end of the anaesthesia. Shocked patients do well with it (4) and it has been recommended for use after haemorrhage. It is very useful in cases blanched from haematemesis (5). Its disadvantages are its uncertain power of producing muscular relaxation and its sensitising effect on the cardiac automatic conductive tissue, this being still-further increased by the presence of adrenalin. The addition of small quantities of ether vapour greatly aids relaxation, while it minimises cardiac irregularities. Capillary oozing is increased in light cyclopropane anaesthesia, because it causes an increase in the systolic blood pressure together with peripheral vaso-dilatation. These changes are not present however when the anaesthesia is deepened. It has been shown that circulatory complications, which may persist into the post-operative period, such as tachycardia, alteration in the blood pressure or cardiac arrhythmia, or shock, are more frequent after cyclopropane than after ether, even in healthy subjects (6). On the other hand, the respiratory morbidity is less than with either ether or spinal analgesia (7). The pneumonia rate was less than one-third of that seen after ether in a large series of upper abdominal cases (6).

Arrhythmias are most common in sthenic and neurotic adults between fifteen and fifty (8). They can be minimised by using evipan or pentothal for induction. They usually take the form of ventricular extrasystoles and may show clinically either as a bigeminal pulse or as a total irregularity. A-V nodal rhythm can occur, but is undetectable by the finger and stethoscope and there is no evidence that it is dangerous. Ventricular extrasystoles associated with cyclopropane anaesthesia are probably of a reflex nature involving the hypo- 
thalamus, and commonly appear at about the level of respiratory arrest, i.e. when the alveolar concentration of cyclopropane is 20 to 30 per cent. Higher concentrations, such as 50 to 70 per cent abolish the irregularity in the majority of cases. In spite of the bizarre character of the pulse there is no evidence of myocardial depression except in the presence of anoxia. The combination of deep cyclopropane anaesthesia with anoxia is very dangerous. Arrhythmia is more dangerous in ascent from than in descent to deep anaesthesia. A moderate slowing of the pulse can be regarded as a normal response, but a bradycardia below fifty a minute will probably develop either into an arrhythmia or into a ventricular tachycardia with a pulse rate of over two hundred, if cyclopropane is further pushed.

Controlled breathing is a useful technique in gastric surgery and can be easily employed with cyclopropane. It can be produced by either of two methods or by a combination of the two. The patient's carbon dioxide can be lowered by pressure on the breathing bag during inspiration, with the soda lime in circuit, i.e. by hyperventilation, until the alveolar, and thus the blood carbon dioxide, is no longer in sufficient amount to stimulate the respiratory centre, and spontaneous breathing ceases. By the second method, the respiratory centre is deliberately depressed by pre-operative omnopon and pentothal, and cyclopropane is given until breathing stops. After this interchange of gases. is then kept up by regular manual compression of the breathing bag so that the frequency and depth of respiration is under the control of the anaesthetist. Guedel states that every patient can be relaxed completely with cyclopropane if controlled breathing is used to push sufficient cyclopropane into his tissues. Providing he is kept fully oxygenated and his arteriolar-capillary refill time does not unduly lengthen, Guedel believes that no harm will come to him. This is an extreme view and may be a true one, but I feel that in the present state of our knowledge a more conservative attitude should be adopted and every effort made to keep the cardiac action normal in rate and rhythm. I prefer to augment relaxation, should this be necessary, by the addition of a little ether, rather than push the cyclopropane to the arrhythmic level.

The type of patient likely to develop arrhythmia is the type that may show emergence delirium or great restlessness immediately following the operation. Occasionally patients who have had deep cyclopropane anaesthesia become shocked on their return to the ward, and may need intravenous fluid.

The most useful signs of anaesthesia with this gas are the degree of activity of the respirator centre, the state of the peripheral circulation, and the degree of muscular relaxation. Cyclopropanes can be combined with spinal analgesia or with abdominal field block, in which case the depth at: which arrhythmias occur need not be reached while consciousness is quickly regained so that the patient can be stirred up soon after operation.

\section{B. Intravenous.}

Pentothal sodium is not irritant to the respiratory tract, and produces only moderate changes in body chemistry. Furthermore, with a free airway respiration is quiet. It is, however, seldom adee quate for gastric surgery when used alone, as the large doses required to produce relaxation cause too much respiratory and post-operative depressioris Combined with nitrous oxide and plenty of oxyge $\overrightarrow{0}$ (20 to 50 per cent) pentothal may be satisfactor for quick operations in debilitated or asthenif patients.

It forms a pleasant induction to general anaes thesia and can be used to give a short period of relaxation if this is required quickly during the operation. Many of these dyspeptic gastric patients are edentulous and lend themselves after prelib minary topical laryngeal analgesia to intubationt through a laryngoscope after the injection of abgut $0.5 \mathrm{gm}$. of pentothal, followed immediately oby cyclopropane or ether. Pentothal combines with abdominal field block and with spinal ana gesia, especially if gas and oxygen are added, bug I prefer to use cyclopropane to supplement thes techniques.

\section{Spinal Analgesia.}

This method is indicated in strong, musculair patients, and in some with active pulmonary tuberculosis, bronchiectasis or acute bronchitis. Analgesia must reach to the fourth or fifth dorsal roots so that the spinal nerves supplying the skign and muscles of the anterior abdominal wall may be blocked, as well as the rami communicantes carrying visceral impulses from the upper abdominal organs. The higher the level of analgespa the greater the risk of circulatory depression and post-operative pulmonary complications. Traos tion on the stomach and mesentery may cause. nausea and retching by reflexes involving the vagus nerves, and for this, as also for psychologicing reasons, it is desirable to combine light genetal anaesthesia with the high spinal block. Cyciopropane is to be preferred in this case, as with anoxia is minimised, and should the spinal analgesia be short-lived, the production of quiet breathigg 
and relaxation can be taken over more easily and safely than by pentothal sodium.

During spinal analgesia the blood pressure must be charted regularly. In cases where shock is anticipated an intravenous drip can be set up. Methedrine is useful to combat hypotension, while the continuous adrenalin drip (9) works well in patients - who are not receiving cyclopropane. Hypobaric nupercain can be used according to the techniques of Howard Jones (I0) or W. Etherington Wilson (II), while Lake's method is a good one for operations lasting up to one hour (I2).

The introduction by Lemmon of his method of serial or continuous spinal analgesia (13) was a valuable addition to the technique of spinal analgesia. By its use the effects of procain, the least toxic of all spinal analgesic drugs, can be maintained for as long as may be necessary, while the risks of over- or under-dosage are abolished. Extra equipment is needed and there are some technical difficulties to be overcome, but it is a useful method which should be used more frequently (I4).

\section{Regional Analgesia.}

This may be used alone, or in combination with light general anaesthesia to improve relaxation and lessen the amount of general anaesthetic necessary. It may take the form of abdominal field block ( $\left.I_{5}, I_{6}\right)$, posterior intercostal block (I7), lateral intercostal block (I8) or rectus sheath block. In the absence of general anaesthesia, splanchnic block is required in addition.

Regional analgesia is the method of choice in poor-risk patients, but is time-consuming. The technique requires practice and in the obese may be difficult to accomplish faultlessly. In the hands of experts, good operating conditions are regularly obtained, but the anaesthetist employing the method occasionally will not always obtain such good results. If regional analgesia is to be used with a general anaesthetic, this is induced before the injections are commenced, but in the absence of general anaesthesia the patient must be well tranquillised beforehand with omnopon or omnopon and nembutal. Extra omnopon can be given in the theatre in doses of gr. $\frac{1}{6}$ intravenously. The legs and arms must be comfortably secured to prevent the patient from moving.

Regional analgesia of the upper abdominal wall entails the blocking on each side of the lower six dorsal nerves, which convey both motor and sensory fibres; while analgesia of the upper abdominal viscera involves blocking of the splanchnic plexuses, either by the surgeon from the front (I9), or by the anaesthetist from the back $(20,17)$. The dorsal nerves can be reached in their subcostal grooves, four finger-breadths from the spinous processes (I 7 ) or in the mid-axillary line (I8). Five to ten c.c. of analgesic solution being injected into the vicinity of each nerve.

The technique of abdominal field block has been well described by Labat (I5), Finsterer (I6) and Maingot (2I). Tovell and Hinds (22) describe a useful and simple method which combines light cyclopropane anaesthesia with a costoiliac block on each side. The analgesic solution is deposited beneath the deep fascia at points two inches apart along lines running from the ensiform, below the ribs and along the flanks to the anterior superior spines. Finally, injections are given into each rectus muscle. Each one of this series of injections consists of Io c.c. of I per cent procain solution with $I: 40000$ cobefrin.

Another good procedure is to aid the poor relaxation afforded by a light general anaesthetic by injections into the rectus sheath on each side of IOO-200 c.c. of $I$ : I00O solution of anethaine (Figs. I and 2). Five or six injections, each of I5 c.c. of solution, are placed in the rectus sheath close to its outer border where the dorsal nerves enter it. The highest injection is just below the ensiform, and the lowest is half-way between the umbilicus and the pubis. At least one injection should be made between the tendinous intersections (23), of which there are usually three, one just inferior to the ensiform, one level with the umbilicus, and the third midway between the other two. A wider zone of relaxation is produced if in addition a costo-iliac block is performed. Solution is deposited deep in the muscular planes, as the nerves run between the internal oblique and transversus muscles. Anethaine I : Iooo solution lasts longer than procain but is more toxic, and 300 c.c. should not be exceeded, physically handicapped patients receiving much less. The addition of 0.25 c.c. of I : Iooo adrenalin to the 300 c.c. makes the agent last longer and reduces toxicity.

Regional analgesia is very useful in operations for repair of perforated ulcers and in wounds involving the upper abdomen. In these cases the addition of light general anaesthesia, especially cyclopropane, is often preferable to the large doses of omnopon, etc., which may be needed in its absence.

\section{Factors Influencing the Choice of Anaesthetic}

Each anaesthetic agent and method varies in its capacity to upset the function of both normal and pathological organs, and no single agent is satisfactory for routine use. The type of patient, 
including his physique, habits and general health, may vary as also the nature and probable duration of the operation.

Good relaxation is the first essential and is therefore the most important factor governing the choice of anaesthetic technique. The ultimate choice depends on the amount of relaxation demanded by the surgeon and the price one is prepared to pay for it (22).

Fit men who are at the same time tough and muscular, usually do well with spinal analgesia and cyclopropane light general anaesthesia. Healthy patients of both sexes with average physique, can be managed well with cyclopropane and minimal ether if necessary; with gas oxygen ether; or with rectus sheath block, abdominal field block or intercostal block combined with either of these methods of general anaesthesia. The type with flabby abdominal muscles does well with cyclopropane in concentrations which do not effect the heart. Finally the poor-risk case, lacking in muscular tone and vitality, can often be carried along with continuous pentothal and gas and oxygen with the addition of a small amount of cyclopropane or ether if necessary. Otherwise abdominal field block with anterior splanchnic block may give the patient his best chance of ultimate recovery.

\section{Prevention and Treatment of Some Operative and Post-operative Com- plications}

Shock.

Early recognition is helped by regular observation and charting of the blood pressures and pulse rate. Early intravenous therapy should be proceeded with, while methedrine given intravenously or intramuscularly may be useful (24). The head should be tilted below the level of the pelvis.

\section{Spillage of Gastric Contents.}

A Ryle's tube is passed into the patient's stomach before he comes to the theatre so that the stomach can be washed out and emptied. Aspiration is intermittently employed by the anaesthetist until the anastomosis is commenced. Before the clamp is applied, the tube is pulled clear into the proximal part of the stomach.

\section{Pulmonary Complications.}

These must be expected frequently (25) after gastric operations and may follow any agent or method of anaesthesia. They take the form of the bronchitis-atelectasis-bronchopneumonia syndrome and are more frequent in old debilitated patients than in the young and vigorous. Symptoms com-ฏ mencing during the first four days are likely to be due to collapse, while those occurring after the fourth day will probably be due to bronchitis or bronchopneumonia.

Primary atelectasis ranging in size from isolated patches to massive collapse of a whole lobe may, if unchecked, lead to bronchopneumonia. It is due to the combination of bronchial obstruction $\frac{\bar{\sigma}}{-}$ by mucus plugs, with reduced respiratory move- $-\overline{0}$ ments consequent on depression of the respiratoryy centre and pain from the operation area. Splinting of the diaphragm by binders, unwillingness to? cough up gathering sputum, and the use of opiates $\vec{\omega}$ are additional factors, while the degree and dura- $\omega$ tion of atony of the diaphragm and intercostals, during and after operation, also influence the 3 . condition.

Acute upper respiratory tract infections should $\vec{\sim}$ contra-indicate all but life-sàving operations, while $\omega_{\omega}^{\omega}$ patients with.chronic productive cough should be made as safe for surgery as possible by attention $\odot$ to their general health and habits, and by avoiding operation.in cold, damp weather.

At the end of the operation Tracheo-bronchialsuction should be carried out in all cases in which $\subsetneq$ rattles or bubbles suggest that there is anything toक aspirate, while inspiration of vomitus should call for $\overrightarrow{0}$ bronchoscopic suction.

Stimulation of coughing and deep breathing; with change of posture every hour-the so-calledio shake-up treatment-should be zealously employed by the nursing staff in the immediate post-operative $\overline{\bar{O}}$ period. The sooner a patient can be stirred upo and his lung bases adequately ventilated after his $\stackrel{2}{ }$ return from the theatre, the less likely is he to $\overrightarrow{\overrightarrow{0}}$ develop chest complications.

If atelectasis persists in spite of the shake-up and of sharp clouts on the affected side of the chest designed to dislodge plugs of mucus, suctionthrough a nasotracheal tube passed blindly after 3 . topical laryngeal analgesia, will often help the $\frac{\sigma}{3}$ condition and may need to be repeated. Broncho- $\stackrel{3}{\circ}$. scopic suction under direct vision should be $\stackrel{\odot}{8}$ reserved for the worst cases.

\section{REFERENCES}

I. ADAMS, R. C. (1942), Chapter on Anaesthesia in Carcinoma of Stomach. Waltman, Gray and Priestly (W. B. Saunders Co., $\mathrm{N}$ Philadelphia and London).

2. MORTON, H. J. V. (1944), Lancet 1, 12. March I8th.

2. MOVELL, R. M., and HICKCOX, C. B. (1942), Can. Med. Assoc. N Jour., 46. Jan.

4. BEECHER, H. K. (1943), J.A.M.A., 121, 899. March 2oth. N

5. HERSHEY, S. G. and ROVENSTINE, E. A. (1944), A naesthesiology,

6. EISENHART, C., SIMPSON, R. A., and GILLESPIE, N. A. (I943), Br. J. Anaes., 17, 4. July.

7. WATERS, R. M. (1936), B.M.J., 2, ror3. Nov. 2 ist.

8. GUEDEL, A. E. (1940), A maesthesiology, 1, r. July.

9. EVANS, FRANKIS (I944), Lancet 1, I 5. Jan. Ist.

9. JONES, W. HOWARD (1930), Br. J. Anaes. 7, 99. April.

ro. JONES, W. HOWARD (1930), Br. J. A naes. 7, 99. April.

12. LAKE, NORMAN (1944), Proc. Roy. Soc. Med., 37, 9. July. 
13. LEMMON, W. (1940), Ann. Surg., 3, 141-144. Jan.

14. LEE, J. ALFRED (1943), Lancet, 2, 156 . Aug. 7th

15. LABAT, G. (1930), Regional Anaesthesia (W. B. Saunders Co., Phila-



I6. JAMES, N. R. (1943), Regional A nalgesia for Intra-abdominal Surgery (J. \& A. Churchill, London), p. 23.

18. BARTLETT, R. W. (1940), Surg. Gyn. and Obst., 71, 194.

19. FINSTERER, H., and THOREK, P., Am. J. Surg. 25 (n.s.), $48 \mathrm{r}$ Sept., 1934 .
20. LUNDY, J. S. (1942), Clinical Anaesthesia (W. B. Saunders Co., Philadelphia and London), p. 159.

21. MAINGOT, RODNEY (194I), The Technique of Gastric Operations

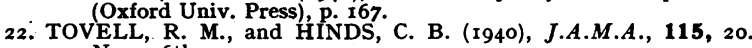
Nov. 16th.

23. ALCOCK, HELEN BOWER (1943), Post-Grad. Med. Journal, 19, 212. July.

24. DODD, H. (1943), B.M.J. March 3oth.

25. MIMPRISS, T. W., and ETHERIDGE, F. G. (1944), B.M.J. Oct. 7th.

\section{GASTRIC AND DUODENAL ULCER-Part II}

In the July issue the surgical aspects of gastric and duodenal ulcer will be dealt with by RODNEY MAINGOT and A. K. MONRO and the Journal will be most beautifully illustrated with drawings made during the course of various operations.

\section{It is hoped that this number will be published within a few days so that the two parts may be read together.}

\section{EDITOR.}

\section{NEW PUBLICATIONS}

J. B. Lippincott Company will shortly be publishing the following:

\section{SURGERY OF THE HAND}

By Sterling Bunnell, M.D. 597 Illustrations. Price 72s. net.

Primarily this book was designed to treat reconstruction alone, but it has been expanded to include a little of other aspects that seemed necessary. It is with a desire to aid in the increasing work of restoration of usefulness to injured hands that Dr. Bunnell has written this great book.

\section{MEDICAL USES OF SOAP}

Edited by Morris Fishbein, M.A. 4I Illustrations. Price I8s. net.

Many scattered articles have appeared on specific medical uses of soap, but never before has a reference, written by leading authorities, so adequately covered this field. This series of articles answers many of the questions as to the effects of soap on the normal skin and hair, on the abnormal skin, the effects of soaps used in shaving and shampooing, and irritation produced by soap under various conditions.

\section{A STUDY OF ENDOMETRIOSIS, ENDOSALPIN- GIOSIS, ENDOCERVICOSIS, AND PERITONEA- OVARIAN .SCLEROSIS}

\section{A Clinical and Pathological Study}

By Dr. James Robert Goodall. I3 illustrations in black and white and $\mathrm{I}_{7}$ subjects in full colour on 6 plates. Second edition. Price 35 s. net.

In this second edition there is a new chapter on the interesting urinary complications arising out of pelvic endometriosis. The author, in his further research, has found only corroborative evidence to substantiate the facts and opinions expressed in the first edition.

\section{BOOK REVIEW}

\section{LOCAL ANAESTHESIA: BRACHIAL PLEXUS}

By R. R. Macintosh, M.A., M.D., F.R.C.S., D.A., and W: W. Mushin, M.B., B.S., D.A. Published by Blackwell, Ltd., Scientific Publications, Oxford. Price Ios. 6d.

This is a most interesting and entertaining little book, containing many innovations in its fifty-six pages. The authors have realised that the best way to learn is by watching the master doing his work and they have, therefore, by means of interesting photographs and diagrams, shown quite graphically the method of pro- ducing brachial plexus anaesthesia, using relatively few words to describe the operation.

The reviewer found himself able to perform a very successful brachial block after reading through the text and studying the pictures for but a short while. This then is the best recommendation that can be given to it.

The book has been written entirely from the practical angle, and from this angle it certainly succeeds in doing what it set out to do, namely, to teach the uninitiated the method of performing this very interesting form of local anaesthesia.

It is to be recommended. 